\title{
PARA CADA TEMPO, UM LEITOR ${ }^{1}$
}

\author{
Andreia Silva De Negri ${ }^{2}$ \\ Flávia Brocchetto Ramos ${ }^{3}$ \\ Lucila Guedes de Oliveira ${ }^{4}$
}

\begin{abstract}
A contemporaneidade do olhar se surpreende com o aparentemente desconhecido. $O$ que vivifica as imagens junto ao imaginário e a memória futura dos pequenos e jovens leitores são justamente essas experiências visuais ocultas que não foram ainda conscientemente vividas por eles. (OLIVEIRA, 2008, p. 43).
\end{abstract}

\section{Resumo}

A literatura infantil contemporânea é um produto cultural híbrido e se constitui também pela atualização de outros textos que precedem a publicação mais recente. Desse modo, analisa-se, com base em pressupostos bakhtinianos, a narrativa Ervilina e o Princês ou Deu a louca em Ervilina (ORTHOF, 2009), para discutir prováveis interações entre texto (verbal e visual) e leitor. Da análise, são apontadas propostas de sentido que subjazem ao livro, discutidas relações entre o texto contemporâneo e o fonte - "A princesa e o grão de ervilha", de Andersen (2004), como também entre as duas edições de Orthof. O estudo está inserido em investigações que buscam aproximar obras literárias do leitor infantil, no espaço escolar, a

\footnotetext{
${ }^{1}$ A primeira versão deste texto foi publicada nos anais da X ANPED SUL Florianópolis. Estudo produzido na Universidade de Caxias do Sul, no âmbito das pesquisas Desafios e acolhimentos da literatura infantil: a mediação de leitura literária, aprovada pelo Edital 04/2012- PqG/FAPERGS, e Narrativa visual no PNBE 2014: composição e leitura, aprovada pelo Edital CNPq n ${ }^{\circ} 43 / 2013$ - Ciências Humanas, Sociais e Sociais Aplicadas.

${ }^{2}$ Graduada em Letras. Mestre em Educação pelo PPGEd UCS, professora da Rede Municipal de Caxias do Sul. Endereço: Universidade de Caxias do Sul / Bloco E- Mestrado Educação) Rua Francisco Getúlio Vargas, 1130 Petrópolis, Caxias do Sul - RS, 95070-560. E-mail: andreia dn@ hotmail.com

${ }^{3}$ Doutor em Letras pela PUCRS e docente e pesquisadora no PPGEd e PPGL na Universidade de Caxias do Sul. Endereço: Rua Francisco Getúlio Vargas, 1130 - Petrópolis, Caxias do Sul - RS, Brasil. 95070-560. E-mail: flaviaramospesquisa@gmail.com

${ }^{4}$ Graduada em Arte. Mestre em Educação pelo PPGEd UCS - Professora da Rede Municipal de Caxias do Sul e Farroupilha. Endereço: Universidade de Caxias do Sul / Bloco E- Mestrado Educação) Rua Francisco Getúlio Vargas, 1130 - Petrópolis, Caxias do Sul - RS, Brasil 95070-560. E-mail: lucilaguedes@yahoo.com.br
} 
partir da mediação docente, tendo como foco práticas de linguagem que podem promover a experiência estética e o letramento literário.

Palavras-chave: Literatura infantil; Letramento literário; PNBE; Infância

\section{HISTÓRIA....}

A literatura para criança nasce no momento em que a palavra circula no livro impresso, e o livro para a criança brasileira vai se consolidando num cenário onde os recursos tipográficos eram restritos. Apenas com a vinda da Família Real, em 1808, começa a firmarse o cenário em que as práticas de leitura vêm se constituir. Assim, na história da literatura infantil brasileira, alguns pontos entram em sua formação. Além de sentimento específico em relação à criança, era necessário sistema que possibilitasse a produção, a publicação e a circulação de livros. Os primeiros livros que aqui circulam são importados e tingem o leitor brasileiro com a cultura estrangeira. Na base da nossa formação, estão as histórias de Dona Carochinha.

As primeiras obras aqui publicadas referendam o vínculo do livro com a escola, evidenciando caráter educativo. Como exemplo, citamos a primeira obra classificada como poética, editada no Brasil. Trata-se de Flores do campo: poesias infantis, de José Fialho Dutra, publicada em 1882, no município de São Leopoldo, no Rio Grande do Sul. A obra não revela preocupação formal ou temática com o leitor mirim; predomina tom doutrinário que incentiva, por exemplo, o respeito incondicional ao diretor do colégio. Ainda no gênero poesia, Olavo Bilac pode ser considerado best seller no início do século XX com a publicação de Poesias infantis (primeira edição em 1904). Bilac explora recursos poéticos, em especial a musicalidade; no entanto, conserva nos poemas a vinculação à escola, seja pela temática que retoma datas cívicas, seja por meio da exaltação de comportamentos adequados à criança cortês e educada.

Desse modo, poesia e prosa veiculadas na linguagem verbal oscilam entre viés mais ou menos educativo e vão construindo a literatura infantil brasileira. Desde o final do século XIX e durante todo o século $\mathrm{XX}$, a visualidade vai ganhando espaço e compartilhando sentidos junto à palavra. No que tange à qualidade do texto que almeja ser literário e à participação da visualidade na composição do livro, destacamos título de Monteiro Lobato, que em 1920, publica A menina 
NEGRI, A. S.; RAMOS, F. B.; OLIVEIRA, L. G.

do nariz arrebitado. Na primeira edição da obra, a ilustração comparece com qualidade em harmonia com o texto verbal, como pode ser percebido na capa do exemplar e ainda pela inserção de ilustrações coloridas e pontuais que contribuem para mobilizar o leitor mirim. No âmbito da literatura para criança, a obra lobatiana não inova apenas pela qualidade da ilustração colorida que dialoga com a palavra ampliando sentidos; Lobato cria obra privilegiando a cultura local, mas dialogando com a tradição europeia.

$\mathrm{Na}$ obra infantil do autor, comparecem Dona Carochinha, princesas dos contos de fadas, Peter Pan, vilões como Barba Azul, ao lado do Saci, de tio Barnabé, vivendo aventuras tanto no sítio de Dona Benta - cenário brasileiro - como realizando incursões em outros espaços. No título em questão, Lobato cria histórias priorizando a intertextualidade muito antes de o termo ser cunhado, e esse modo de fazer literatura infantil foi assumido por outros escritores.

Elege-se, neste artigo, título de Sylvia Orthof ${ }^{5}$, que como a obra escrita por Lobato e aqui citada, articula elementos da cultura local com a europeia, tradicionalmente destinada à criança. A diversidade da obra da autora contribui para a valorização da leitura, priorizando a compreensão e construção de sentidos, e põe em cena múltiplos modos de ler, que podem ampliar a visão de mundo do leitor. Pela contribuição da obra da escritora à cultura brasileira, elege-se um dos seus títulos para estudo, a fim de responder ao problema: Como a obra literária Ervilina e o Princês ou Deu a louca na Ervilina ${ }^{6}$ constitui-se, discursivamente, e poderia propiciar situações de letramentos no cenário escolar. O título foi selecionado pelo Programa Nacional Biblioteca da Escola/2010 - PNBE - para compor acervo de anos iniciais do Ensino Fundamental

Este artigo inicia a discussão acerca da proposta de interação presente no título, a partir de considerações a respeito do papel do leitor na concretização do texto. Em seguida, amplia a reflexão para elementos do contexto histórico de origem e regularidades da modalidade discursiva pela qual se constitui a história, no caso, a narrativa, tendo como referência os pressupostos bakhtinianos. Por fim, as relações do discurso da narrativa de

\footnotetext{
${ }^{5}$ Sylvia Orthof, filha de imigrantes, nasceu em 1932 e faleceu em 1997, ganhou muito prêmios pela produção destinada à criança. Fundou, em 1975, a Casa de Ensaios Sylvia Orthof, que produzia espetáculos infantis. Em 1975, foi convidada a escrever um conto para a revista Recreio. Seu primeiro livro foi lançado em 1981: Mudanças no galinheiro mudam as coisas por inteiro. A mosca Zenilda (que recebeu o Prêmio Jabuti de Melhor Produção Editorial), Maria vai com as outras e Fada Cisco Quase Nada. Faleceu em 1997, deixando mais de cem livros publicados para os pequenos leitores. Disponível em: http://www.atica.com.br/SitePages/autores.aspx?Autor=809. Acesso em: 01/04/ 2014.

${ }^{6}$ Por fins práticos, no corpo do artigo acolhemos o uso somente da parte inicial do título da obra, no caso, Ervilina e o Princês.
} 
PARA CADA TEMPO, UM LEITOR

Andersen e as duas versões da obra de Orthof são apontadas possíveis potencialidades de depreensão de sentidos originadas da interação entre esses textos e o leitor infantil.

\section{LEITOR}

A partir de contribuições de Bakhtin acerca da linguagem e de seu caráter dialógico, entende-se a leitura como uma atitude responsiva do leitor ao texto. O processo de compreensão de um texto, para este autor, é uma atividade que envolve o sujeito e as experiências sócio-históricas e culturais que o constituem. A definição simplista do ato de ler não contempla a complexidade pela qual o processo de leitura se constrói, já que não permite ao leitor dialogar com o texto. Nesse sentido, Martins (2006) defende que a leitura vai além do texto

[...] (seja ele qual for) e começa antes do contato com ele. O leitor assume um papel atuante, deixa de ser mero decodificador ou receptor passivo. E o contexto geral em que ele atua, as pessoas com quem convive passam a ter influência apreciável em seu desempenho na leitura. (MARTINS, 2006, p. 33).

Nessa perspectiva, o caráter subjetivo do leitor, ao interagir com a linguagem verbal e visual, atua na significação de uma obra. De acordo com Bakhtin (2003), a linguagem está em toda a parte e viabiliza a prática social, permitindo elaborar sentidos para o mundo. Por ela, os sujeitos se constituem, assim como estes a constituem de forma dinâmica, inseridos na história e na cultura de cada tempo e espaço social. Para o filósofo russo, os indivíduos são seres formados discursivamente pela linguagem, pelos vários discursos que ouvem e proferem.

O discurso, concebido como manifestação concreta da linguagem, revela-se pela língua em uso, sempre contextualizado social e historicamente por quem enuncia, assim como por quem a ele responde. Todo ato de fala pressupõe resposta, e esta é entendida como atividade de atribuição de sentidos. Essa postura ativa, de reação, é denominada, na perspectiva bakhtiniana, atitude responsiva, fruto de um movimento recursivo da linguagem. Para o autor, "cada enunciado é um elo na corrente complexamente organizada de outros enunciados" (BAKHTIN, 2003, p. 272), em que se apagam as fronteiras entre o presente, o passado e o futuro. O discurso atual responde a discursos anteriores, e a relação entre enunciados é entendida como dialógica, uma vez que, com exceção do Adão mítico, que seria 
NEGRI, A. S.; RAMOS, F. B.; OLIVEIRA, L. G.

o primeiro a colocar a palavra ao mundo (BAKHTIN, 2003), nós somos atravessados por discursos de outrem. Todavia, se por um lado nossos discursos, concretos e históricos, contemplam discursos alheios, já proferidos por outro, há que se considerar: cada enunciado é sempre novo e único, pois os momentos não se repetem, e os enunciadores não são os mesmos (em pessoa ou em experiência).

Desse modo, a arte, enquanto linguagem, carrega consigo discursos que contribuem para a formação humana, seja pelo caráter subjetivo, capaz de gerar sentimentos de reconhecimento e identificação, seja por desencadear entendimento da realidade. Duarte explica que a arte

[...] é sempre produto de uma cultura e de um determinado período histórico. Nela se expressam os sentimentos de um povo com relação às questões humanas, como são interpretadas e vividas em seu ambiente e em sua época. Através da arte temos acesso a essa dimensão da vida cultural não explicitamente formulada nas demais construções racionais (ciência, filosofia). (DUARTE JUNIOR, 2002, p. 18).

Logo, a literatura, na condição de manifestação artística pela palavra, é produto de certa cultura e pode desencadear sentimentos e emoções, que possibilitam ao leitor refletir acerca de si e do mundo. A obra literária, portanto, é um discurso que atua na constituição humana do leitor, pois pressupõe uma resposta deste, que faz uso de sua experiência para atribuir sentidos ao dito e ao não dito na ficção. Como a literatura: "[...] sintetiza, por meio dos recursos da ficção, uma realidade que tem amplos pontos de contato com o que o leitor vive cotidianamente.” (ZILBERMAN, 1998, p. 22), reitera-se que o texto literário expressa o humano, oferecendo recursos para compreendê-lo, por meio de concepções artísticas e culturais veiculadas, simbolicamente, pela linguagem.

\section{NARRATIVA}

Dentre os discursos que afetam os leitores na sociedade globalizada, elegemos o narrativo. A narrativa está presente em todas as sociedades, tempos e lugares; começando com a própria história da humanidade, tudo o que se conta é narrativo. A Bíblia Sagrada, por exemplo, narra um modo de conceber o surgimento do homem. A criança, mesmo com restritos recursos linguísticos, põe-se a contar o que percebe e como se percebe nas situações vividas. Pelo narrar, as pessoas vão entendendo o seu entorno e se entendendo; pelas diversas 


\section{PARA CADA TEMPO, UM LEITOR}

formas de expressão, incluindo a narrativa, as pessoas vão se configurando e construindo suas identidades.

Os primeiros estudos da narrativa começaram com a Poética, de Aristóteles, escrita em torno de 335 a.C., e consideravam-na uma dentre as formas (schemata) de linguagem ${ }^{7}$. A habilidade de narrar, específica do ser humano, é parte integrante da sua competência linguística e simbólica. De acordo com Barthes (1971):

[...] não há em parte alguma povo algum sem narrativa; todas as classes, todos os grupos humanos têm suas narrativas, e freqüentemente (sic) estas narrativas são apreciadas em comum por homens de cultura diferente, e mesmo oposta; a narrativa ridiculariza a boa e a má literatura; internacional, trans-histórica, transcultural; a narrativa está aí, como a vida. (BARTHES, 1971, p. 18).

Os humanos estão imersos em estruturas, pelas quais constroem e expressam sua subjetividade. Nesse jogo, sempre participam também os ouvintes/leitores - a construção de uma narrativa vale-se da cooperação destes, e, como não há narrativa sem narrador e sem ouvinte/leitor, a narrativa verbal é construída dialogicamente, num discurso que vai sofrendo alterações, conforme a situação vivida.

Forster (1969) alerta que uma narrativa tem um elemento fundamental: a história desafia o leitor a conhecer o que acontecerá depois. O leitor vai mergulhando e prendendo-se à história, a fim de desvelar o acontecimento seguinte. $\mathrm{O}$ autor, nesse sentido, ao criar a voz que dá forma ao conflito, no caso, o narrador, leva em conta não apenas uma boa história, mas o modo de dizer, ou seja, tem sensibilidade para escolher estratégias ao dizer, de modo que crie um narrador capaz de envolver o leitor.

A história - sucessão de acontecimentos que formam o conteúdo narrativo - vai sofrendo ajustes e inovações, conforme o público visado. O modo de organizá-la, apresentála, também vai se ajustando à matéria a ser contada e ao interlocutor pretendido, sinalizando o caráter inacabado e novo da narrativa.

Adam (1987), apoiando-se nas ideias de Todorov (2004) ${ }^{8}$, apresenta uma estrutura comum ao texto narrativo tradicional:

\footnotetext{
7 As outras formas de linguagem são o imperativo, o requerimento, a pergunta e a resposta. (ARISTOTELES, 1966).

${ }^{8}$ Para Todorov (2004), “a narrativa se constitui na tensão de duas forças. Uma é a mudança, o inexorável curso dos acontecimentos, a interminável narrativa da "vida" (a história), onde cada instante se apresenta pela primeira e última vez. É o caos que a segunda força tenta organizar; ela procura dar-lhe um sentido, introduzir uma ordem. Essa ordem se traduz pela repetição (ou pela semelhança) dos acontecimentos: o momento presente não é
} 
NEGRI, A. S.; RAMOS, F. B.; OLIVEIRA, L. G.

1) estado inicial (EI): é o início, o começo da história, caracterizado por apresentar os actantes, o lugar e as circunstâncias numa situação estável, equilibrada.

2) força transformadora (FT): introduz força que vai perturbar o equilíbrio do estado inicial. Essa força gera o momento seguinte.

3) dinâmica da ação (DA): é caracterizada por apresentar situações narrativas que ora pendem para a melhoria, ora para a degradação.

4) força equilibrante (FE): introduz uma segunda força que vai devolver à narrativa a situação de equilíbrio, confirmando a melhoria ou degradação na narrativa.

5) estado final (EF): apresenta as consequências possíveis e pertinentes ao que foi estabelecido e apresentado anteriormente, sendo coerente com os quatro momentos que o antecedem, restaurando o equilíbrio perdido, sem ser, obrigatoriamente, igual ao estado inicial.

O modelo tradicional de narrar, presente nos contos populares, segue estrutura clássica. Dentre esses contos, citamos os editados por Hans Christian Andersen. O escritor dinamarquês, reconhecido como fundador da literatura infantil, nasceu na Dinamarca, em 1805. Embora filho de sapateiro, ingressou nos estudos e começou a escrever cedo. Em sua extensa obra dedicada às crianças, predominou o tom romântico e poético. É reconhecido pelos contos de fadas - último estágio de sua produção e, dentre eles, destacamos "A princesa e o grão de ervilha" (ANDERSEN, 2004), para focalizar neste artigo.

O conto segue a estrutura clássica. Um príncipe deseja casar-se com uma verdadeira princesa e, mesmo procurando pelo mundo, não a encontra. Regressa para casa e, em uma noite de temporal, aparece, no castelo, uma jovem pedindo abrigo, que diz ser princesa verdadeira. A rainha desconfia e coloca um grão de ervilha embaixo de muitos colchões, para testá-la. Na manhã seguinte, a jovem reclama de não ter conseguido dormir, porque algo muito duro, embaixo do colchão, provocou-lhe dores nas costas e a deixou com hematomas. Identificada a princesa, "o príncipe a desposou, porque agora ele sabia que tinha encontrado uma verdadeira princesa.” (ANDERSEN, 2004, p. 30)

A história contada por Andersen sofre alterações em relação ao enredo recriado contemporaneamente. Entre as várias versões, elegemos a produzida por Sylvia Orthof. mas se constitui na tensão das duas, [...]." (TODOROV, 2004, p. 22). 


\section{PARA CADA TEMPO, UM LEITOR}

Ervilina e o princês ou Deu a louca em Ervilina, editada inicialmente em 1986 e, depois de ficar vários anos fora de circulação, reeditada com nova roupagem, em 2009. O projeto gráfico do título recebeu ilustrações de Laura Castilhos, por meio de recorte e colagem com papéis diversos e ainda pintados pela ilustradora.

O diálogo da obra objeto de análise, estabelece-se, portanto, com mais de uma fonte. A primeira é o conto de Andersen, publicado ainda no século XIX; a segunda, a atualização da primeira edição da versão de Orthof, editada em 1986, digitalizada e inserida em tamanho reduzido das páginas 42 a 48 do exemplar objeto de análise. Já a terceira possibilidade estabelece-se pela configuração do título atual, por se tratar de narrativa ilustrada e, portanto, construída por meio da linguagem verbal e visual, que interagem, formando objeto artístico híbrido.

\section{NOVA ROUPAGEM: PRINCESA, PRÍNCIPE, PEDREGULHO E ERVILHAS...}

Narrativas contemporâneas tendem a romper com a estrutura do conto clássico e, no caso do livro ilustrado, a multiplicidade de estilos e técnicas empreendem sentidos variados. As implicações do projeto gráfico desses objetos conjugam interações entre texto verbal e visual e, consequentemente, entre o livro-objeto e o leitor. O título de Orthof reúne elementos que o tornam objeto de arte para o público infantil, ao proporcionar reflexão e prazer, assim como a ampliação de conhecimento de mundo, uma vez que constrói narrativa verbal e visual que instiga a imaginação e permite atitude responsiva do leitor.

Escrito em verso, reconta e reinventa, de forma bem-humorada, uma história clássica de Andersen. A escritora mescla elementos novos à história tradicional, que causam graça e surpresa ao leitor. Em exemplar não paginado e com elementos paratextuais (folha de rosto, dados catalográficos, dedicatória), a história é recontada por versos e ilustrações, seguida de dados acerca da autora e da ilustradora e, por fim, as sete últimas páginas contemplam a digitalização da edição de 1986.

A subversão permeia o texto de Sylvia Orthof e Laura Castilhos. O título sugere a retomada lúdica do conto original: a candidata à princesa, Ervilina, ganha esse nome graças a um trocadilho com a ervilha posta pela rainha embaixo dos colchões e o príncipe, depreciativamente, chama-se Princês. A narrativa inicia com caráter metaliterário, anunciando que a história a ser contada, embora seja muito familiar ao universo dos contos de fadas - um 
NEGRI, A. S.; RAMOS, F. B.; OLIVEIRA, L. G.

príncipe solitário em busca de um amor verdadeiro e eterno - será alterada: "Vou contar, cá do meu jeito, / uma história muito antiga, / muito feita de princesa, / história de rei, de rainha, / história toda cantada, / melada de bruxa e fada, / história tão recontada / que resolvi aumentar" (ORTHOF, 2009, p. 4 - grifo nosso). Ou ainda: "Quem conta um conto, aumenta, /um ponto mais, outro mais, /transforma, vira e inventa, / quem conta um conto /refaz" (ORTHOF, 2009, p. 5)

$\mathrm{Na}$ abertura da história, o narrador alerta o leitor acerca do papel que vai desempenhar na narrativa. A singularidade no contar e a possibilidade de subversão são referendadas: "Vou contar, cá do meu jeito" ORTHOF, 2009, p. 4) e ainda justifica a transformação que o enredo inicial vai sofrer: “[...] quem conta um conto / refaz" (ORTHOF, 2009, p. 5). O vínculo com a história original é marcado na abertura da narrativa, evidenciando o caráter responsivo da narrativa reinventada.

Ao final da narrativa, breve biografia da autora e da ilustradora auxiliam a contextualizar a obra. Na página 42, o exemplar veicula capa da primeira edição da obra, na ocasião ilustrada pela própria escritora Sylvia Orthof e, nas páginas que sucedem, a primeira edição do livro, de 1986, é recuperada na íntegra, digitalizada em formato reduzido. A presença do texto da primeira edição reitera o caráter responsivo da edição ilustrada por Laura Castilhos.

$\mathrm{Na}$ versão mais recente, a ilustração prevalece nas páginas e emprega predominantemente o recorte de papel, formando figuras e cenas que pontuam, descrevem ou narram aspectos do enredo. Do ponto de vista da expressão e da narrativa, a composição de figuras isoladas (Fig. 1) sinaliza autonomia e coerência no encadeamento das páginas, ao mesmo tempo em que possibilita ao leitor construir sentidos para a sequência visual da obra.

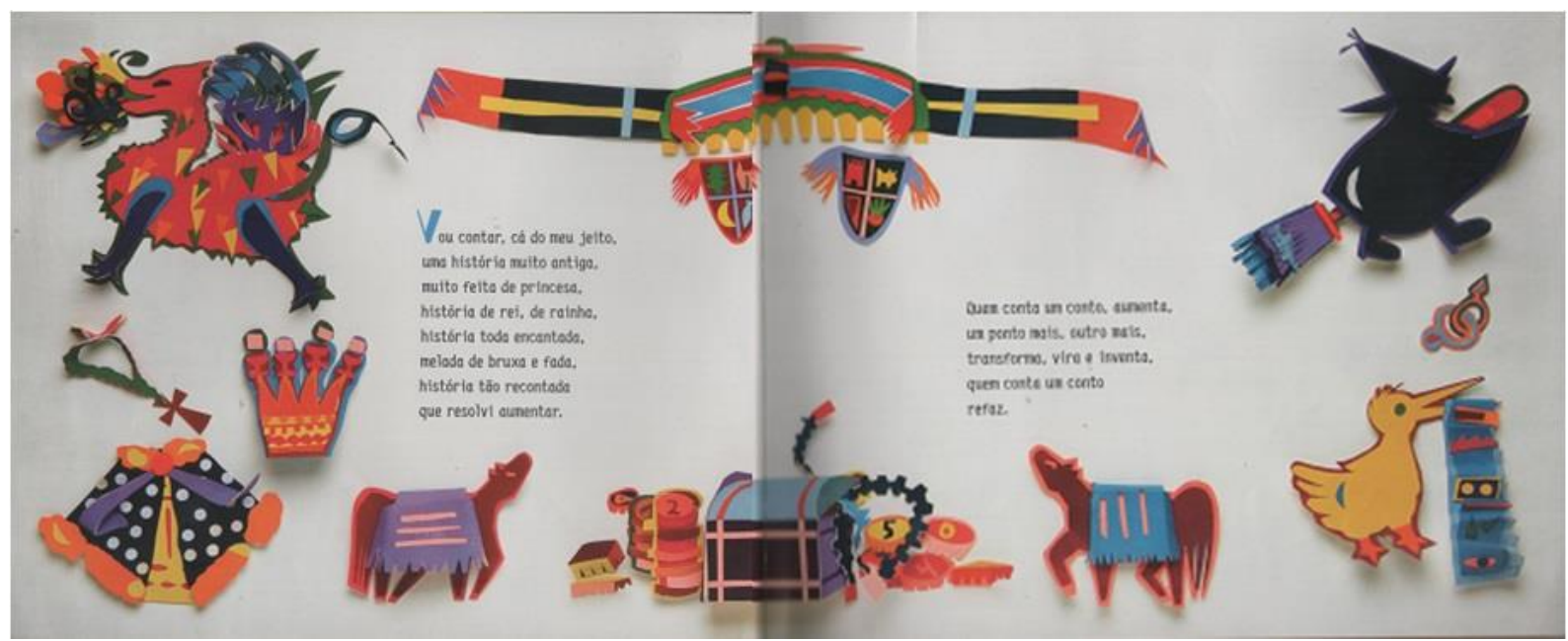


Fig. 1.

Fonte: Orthof e Castilhos (2009, p. 4-5).

O texto de Andersen sofre alterações, privilegiando o humor e a desconstrução da figura do príncipe. Já no título do livro, há inversão no foco: enquanto que na história original o foco é a protagonista "A princesa e a ervilha", na recriação da escritora, o masculino e o feminino são postos no título "Ervilina e o Princês ou Deu a louca em Ervilina" (grifos nossos). A subversão à história tradicional é, pois, anunciada já na capa do exemplar.

Frente à tristeza de Princês, sua mãe interfere: “- Meu filho, ó filho meu, / estás triste, estás sofrendo? / O que foi que aconteceu? (ORTHOF, 2009, p. 10)” E insiste: - Meu filho, o que é que tens, / diga pra tua mãe rainha, / alguma coisa daninha, / alguma tristeza ou mal? (ORTHOF, 2009, p. 15). O filho desabafa: “- Eu me sinto tão sozinho... / eu queria me casar / com uma moça sensível, / que fosse tão delicada, / como se a moça fosse / uma rosa ou uma fada!" (ORTHOF, 2009, p. 15)

No entanto, ao contrário da estrutura dos contos maravilhosos e da versão de Andersen, o jovem não sai em busca de uma princesa; fica em casa, e seus pais se mobilizam: "Seu Rei e Dona Rainha / resolveram procurar, / mandaram vinte ministros, / mais oitenta generais, / botaram um grande anúncio / escrito em dez jornais: / PROCURA-SE UMA MOÇA / QUE SEJA DELICADA [...]” (ORTHOF, 2009, p. 17).

No conto de Andersen, o príncipe almeja uma princesa; na versão orthofiana, ao contrário, muitas jovens buscam se casar com o jovem passivo e passam pelo rito de dormir na cama onde havia uma ervilha embaixo do colchão, sem percebê-la. A rainha, na recriação, tem papel marcante, porque troca a pedra lascada, que havia embaixo do colchão e era ignorada pelas falsas princesas, por ervilha redondinha - percebida pela camponesa, que vem ao castelo a contragosto. A rainha contemporânea é envolta na fantasia, assumindo dimensão etérea. No entanto, ao decorrer da trama, toma postura mais realista.

A recriação potencializa o ilogismo, valorizando a postura responsiva do texto contemporâneo, como se constata na chegada do pai de Princês: "O rei, seu pai, veio chegando / numa carruagem d'água. / Toda feita de cascatas, / cavalos que navegavam / sobre as nuvens tão molhadas.” (ORTHOF, 2009, p. 10). Nesse caso, a ilustração mostra o rei na carruagem, contribuindo para o leitor visualizar a carruagem imaterial. Ademais, o ilogismo inerente ao texto verbal é potencializado pela ilustração, que favorece a concretização da 
NEGRI, A. S.; RAMOS, F. B.; OLIVEIRA, L. G.

palavra, contribuindo para o leitor assumir atitude responsiva ativa, conforme pressupostos bakhtinianos.

Nesse sentido, a obra demanda análise da visualidade. A versão de Orthof (2009) responde humoristicamente a um enunciado anterior, o conto clássico, sendo que o tom que a palavra confere aos personagens encontra eco na ilustração. Aqueles aparecem isolados nas páginas, com poucos elementos dos cenários. Quando a jovem toma banho, por exemplo, vêse que está dentro de uma banheira com espumas, mas não há outros elementos nas cenas que mostrem o banheiro. O silêncio da ilustração, quanto aos detalhes da trama, é ocupado pela palavra, que esmiúça aspectos do enredo. Os personagens são demasiadamente caracterizados, restringindo a atuação do leitor. A rainha (Fig. 2), por exemplo, surge carregada numa rede de estrelas, usando vestido de rendas, coroa de prata, tranças douradas, com anéis de brilhantes e diamantes, braceletes de esmeralda (ORTHOF, 2009, p. 13).

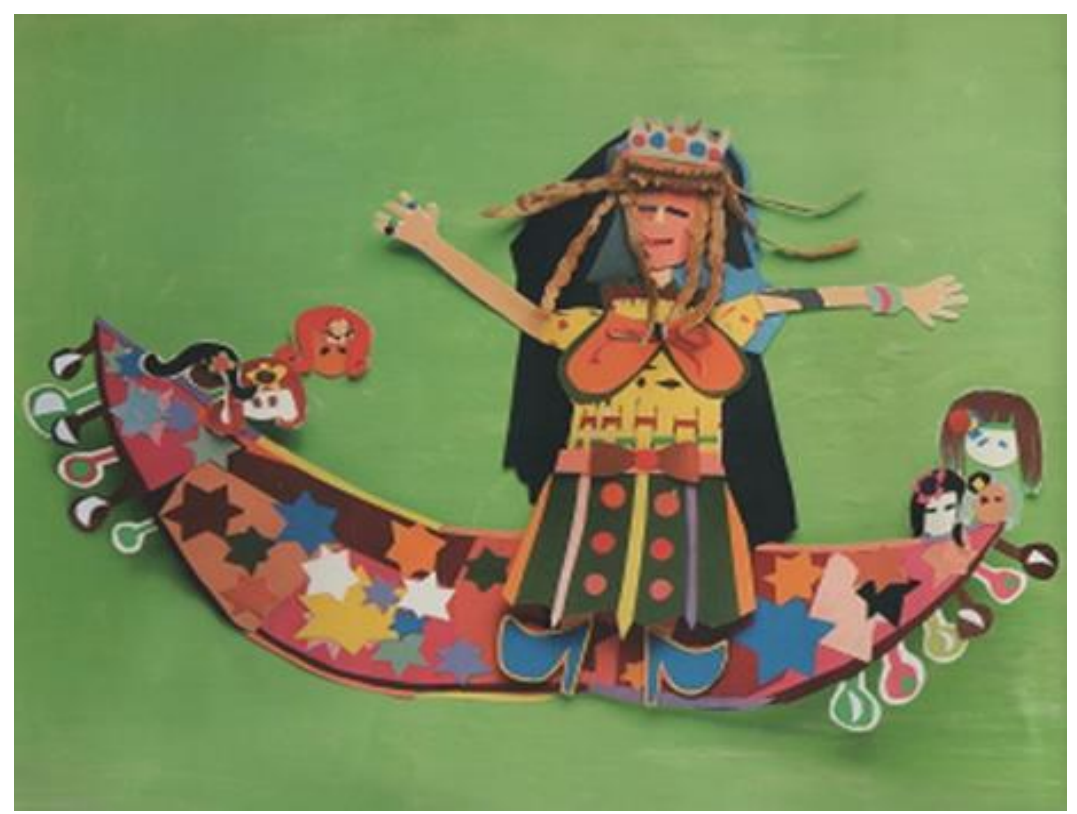

Fig. 2

Fonte: Orthof e Castilhos (2009, p. 12)

Na obra em questão, ainda na introdução do conto, é construída uma atmosfera de ficção, anunciando o ilógico que está por vir: "Pois era uma vez, / um princês,/ filho de um rei irreal, / que morava na montanha/ de pedra lisa e cristal [...]” (ORTHOF, 2009, p. 7). Na sequência, as estrofes são repletas de imagens capazes de provocar a imaginação da criança, enriquecendo seu repertório, como no anúncio da chegada do rei "numa carruagem d'água, / 
toda feita de cascatas, / cavalos que navegam/ sobre as nuvens tão molhadas." (ORTHOF, 2009, p. 10) e da rainha: "E veio chegando a rainha/ numa rede balançando, / a rede era de estrelas, / muitas aias carregando." (ORTHOF, 2009, p. 13).

A marca lúdica evidencia-se pela brincadeira com as palavras, expressa pelas rimas e pelo ritmo presente nos versos curtos. O dinamismo do enredo favorece a adesão do leitor mirim ao fio lúdico e melódico da obra, que muitas vezes lembra o teatro, devido às falas dos personagens com apelo dramático, manifestadas pelo discurso direto. A voz dos personagens é marcada por elementos culturais do contexto de produção do título. Com predomínio da redondilha maior, metro popular que lembra repentes da cultura nordestina, os versos revelam, por exemplo, pais atentos ao sentimento do filho, que procuram descobrir se ele tem "alguma coisa daninha".

Referendando o pressuposto bakhtiniano de que todo o discurso é ideológico, o título contém crítica à tradição, revestida de humor. A subversão do final do conto clássico denota posição contrária ao poder autoritário exercido pelo casal de monarcas, pelo general e pelos soldados que, à força, levam a personagem Ervilina ao palácio, para lá passar a noite: “Até que veio umazinha, / toda pobre e esfarrapada. / Seu nome era Ervilina / da Lima Cunha de Andrada. / Chegou, mas veio afinal, / empurrada por soldados /por ordem de um general." (ORTHOF, 2009, p. 29). A condição física da moça levou a rainha a trocar a pedra lascada que havia embaixo dos colchões e colocar apenas um grão de ervilha, pressupondo que essa não era a companheira ideal para o filho. Após a noite maldormida, devido ao incômodo que lhe causa o pequeno grão de ervilha, o desprezo e a descrença da rainha dão lugar à surpresa e à alegria do príncipe, que conclui ter, finalmente, encontrado a princesa dos seus sonhos.

Contudo, o desfecho da história surpreende, pois a moça não aceita se casar com o jovem, por já ter um namorado, pastor de ovelhas como ela, por quem demonstra ter verdadeiro afeto (essa informação fica evidente no texto visual, em que o namorado aparece no extremo da página 37, pastoreando ovelhas): "Mas a moça respondeu: / - Eu não quero ser casada, / se eu casar, vai ser com o moço / de quem sou a namorada. // E saiu feliz da vida, / foi cuidar do seu rebanho. / A moça era pastora..." (ORTHOF, 2009, p. 36 - 37)

Há subversão do desfecho do conto de fadas original, no qual príncipe e princesa casam-se e vivem felizes para sempre. Neste caso, o antigo se reapresenta a partir de um discurso inovador e desafia o leitor, que traz em sua memória leituras anteriores de contos clássicos com finais previsíveis, privilegiando o casamento. 
NEGRI, A. S.; RAMOS, F. B.; OLIVEIRA, L. G.

A decisão da protagonista, alicerçada em valores de liberdade de escolha e de desapego aos bens materiais, em respeito aos próprios sentimentos, instiga o leitor a refletir sobre essas questões e, consequentemente, a construir ou reconstruir conceitos de ordem social e cultural, ou seja, a obra, enquanto enunciado, provoca uma atitude responsiva em quem a lê. Esse espaço de interlocução que o título possibilita representa momento importante de interação, propício à constituição humana.

A postura de Princês, na última estrofe do texto, marca o final lúdico, rítmico e inesperado do conto, pela aproximação com a cantiga de roda Ciranda, cirandinha: "O Princês ficou sem graça, /detestou a tal história, / chegou na sua janela, / botou a língua de fora, / disse um verso bem bonito, / disse adeus e foi-se embora!" (ORTHOF, 2009, p. 38). O desfecho reafirma o diálogo com a tradição, mas reafirma a autonomia do novo.

\section{DUAS FACES PARA A ERVILINA}

O diálogo entre as duas edições de Orthof é evidenciado nesta parte do artigo. Cotejando as edições, constatamos que houve alteração não apenas nas ilustrações, mas também no texto verbal. Na primeira edição, vários comentários interagem com o leitor, complementando o texto principal, como o que apresenta a ilustração do momento em que a pedrinha é posta debaixo dos três colchões: uma seta aponta para a pedrinha escondida com os dizeres "a pedrinha (secretíssima... psch!)” (ORTHOF, 2009, p. 46).

Outro momento em que o texto visual é potencializado refere-se à faixa segurada pelas aias (página 11 da versão digitalizada e página 44 da edição atual), onde dois enunciados, ideologicamente opostos, coabitam o mesmo espaço discursivo, complementados pelas falas de um pássaro e um caracol, também representantes de discursos opostos. Na edição de 2009, tanto as falas da faixa quanto as falas do pássaro e do caracol foram suprimidas, pressupondo mais espaço para atuação do leitor, já que cada edição conversa com o leitor do seu tempo. Na primeira edição da obra, as imagens do pássaro e do caracol transitam pelas páginas da história, símbolos, respectivamente, de agilidade e de lerdeza.

Outra proposta de diálogo entre a obra selecionada pelo PNBE e a primeira edição refere-se à visualidade. Nesta, a ilustração assume caráter mais narrativo, em virtude do encadeamento de cenas que pode ser percebido entre as imagens, ao contrário da versão mais recente, em que as figuras pontuam alguns aspectos do conflito. A rainha, por exemplo, no 
título ilustrado por Laura Castilhos, aparece ilustrada em três momentos: quando entra no enredo numa rede de estrelas (Fig. 2), no momento em que o texto verbal caracteriza a jovem pastora que é trazida ao castelo (p. 29) e, por fim, quando a narrativa alerta para a intervenção da rainha que troca a pedra pontuda, que fora colocada embaixo do colchão, por um grão de ervilha (p. 31). Afinal, não desejava que a "umazinha/ toda pobre e esfarrapada" (ORTHOF, 2009, p. 29) fosse a esposa do seu filho.

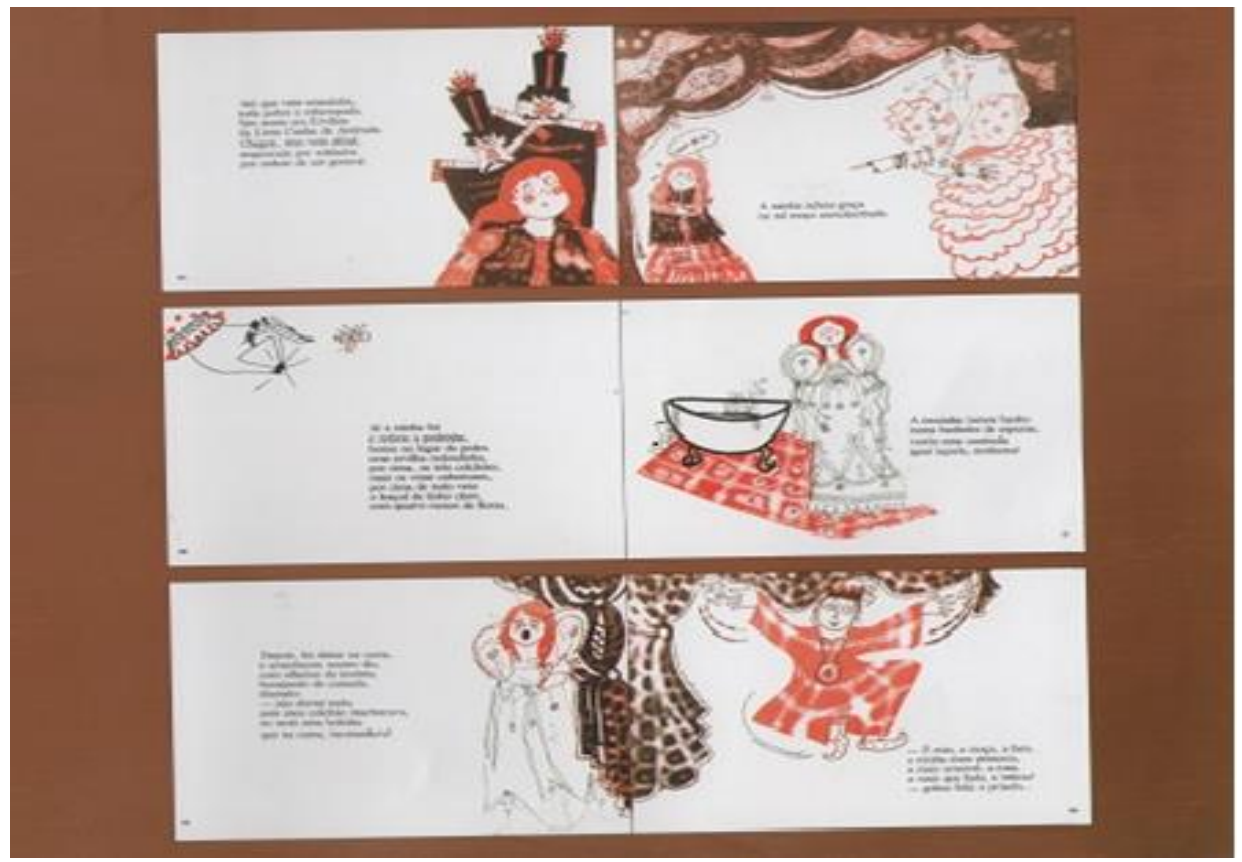

Fig. 3:

Fonte: Orthof e Castilhos (2009, p. 44).

A rainha que tinha formas arredondadas e postura autoritária, na primeira edição (Fig. 3), no exemplar objeto de análise, surge na rede de estrelas, carregada por seis aias de postura subserviente, que aparentam mal conseguirem segurar a alteza, devido ao grande peso (Fig. 3). Ainda na mesma página, logo abaixo do texto, duas aias portam faixa com dizeres de louvor à rainha, enquanto outros dizeres, explicitamente contrários à mesma e em sinal de protesto, são rabiscados. Na reedição, o texto visual privilegia a experiência estética pela escolha de cores fortes e contrastantes e pelas expressões marcantes das personagens. A rainha, ao ver Ervilina da Lima Cunha de Andrada, aperta o nariz, sinalizando que sente cheiro desagradável. Na figura 4, a aparente desordem na composição da imagem de moça com três chapéus, seis pernas e mãos alerta para o dinamismo e o tom lúdico e exagerado do 
NEGRI, A. S.; RAMOS, F. B.; OLIVEIRA, L. G.

enredo. As figuras em papel recortado parecem estar isoladas, requerendo do leitor ação para articular os personagens no enredo.
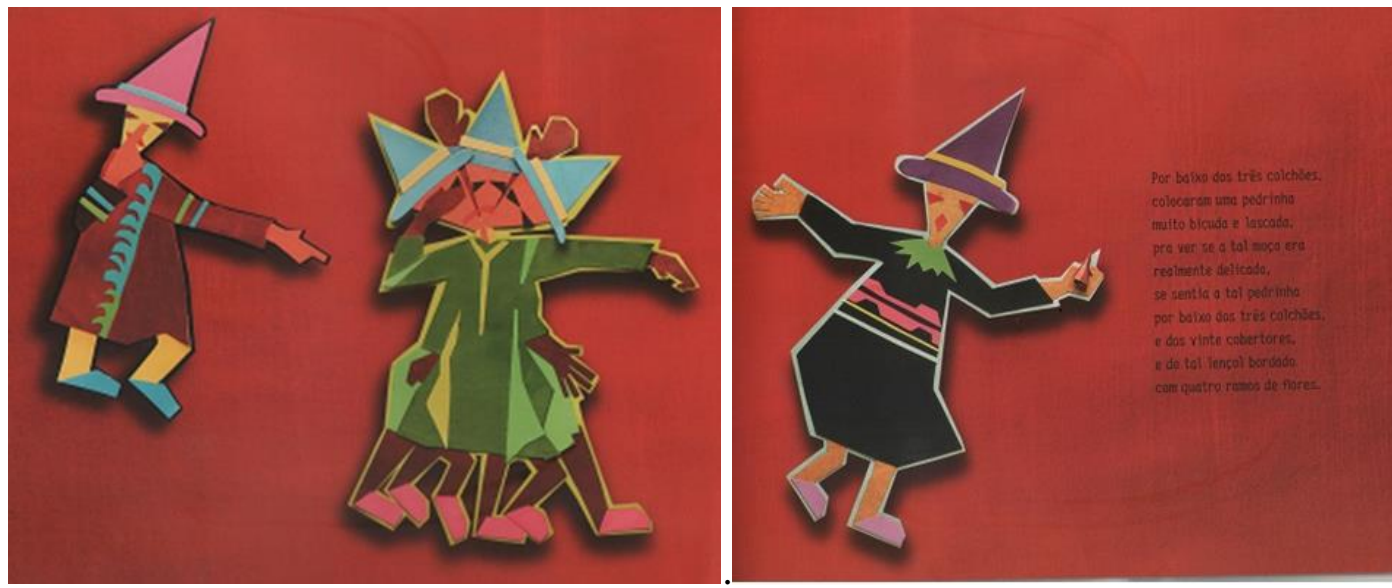

Fig. 4

Fonte: Orthof e Castilhos (2009, p. 22).

A construção de sentidos e a atitude responsiva do leitor podem variar significativamente na leitura das duas versões. Percebemos, ainda, desgaste do discurso da primeira versão do livro, já que hoje o País vive outro momento político. A edição com ilustrações de Laura Castilhos, de certo modo, atualiza o discurso de outrora, já que o texto verbal permanece atual, ao passo que o visual está vinculado a um período específico da história, já superado.

A proposta de dois modos de ilustrar para o mesmo texto verbal gera enunciados distintos. A versão atual apresenta-se essencialmente lúdica, com cores vibrantes e materiais alternativos (dobraduras, recortes e colagens), enquanto que a primeira edição do livro tem postura crítica, de protesto político, coerente com seu tempo de edição. Afinal, conforme Bakhtin, todo discurso é ideológico e está inserido em um contexto histórico e social, em tempo e espaço definidos.

\section{ENCERRANDO A PROSA...}

Discursivamente, a literatura infantil contemporânea se constrói olhando para trás e para frente. Para trás, porque o texto atual busca na tradição motivo para se produzir. No caso da obra de Orthof, o mote é um conto da tradição europeia, amplamente divulgado em vários 
PARA CADA TEMPO, UM LEITOR

países, incluindo o Brasil. A produção da autora vale-se da história de Andersen, mas imprime-lhe cor local e dos tempos presentes, tingindo-lhe de humor.

A composição de Ervilina e o princês toma Andersen como referência e o atualiza, subvertendo a tradição. A obra analisada reitera que cada vez que um título é reapresentado ao público com outro projeto gráfico, retoma o anterior, mas inova. No caso da edição focalizada, observamos agregação de tendência do momento de produção revelada pelo modo como a ilustração se constitui, como também se relaciona com a palavra. A reedição marca a relação dialógica entre dois produtos, pois embora a história verbal seja a mesma, o projeto gráfico é modificado, implicando criação de outra narrativa. $\mathrm{Na}$ versão mais recente, evidencia-se a relação dialógica entre a história revisitada e o conto de fadas clássico.

A visualidade na obra é um aspecto que merece atenção. A interação entre elementos visuais expressa formas de dizer, tendo em vista a especificidade de cada elemento na composição, porque veicula modos de entender e de se posicionar no mundo. A interação entre palavra e imagem do título em análise, configura-se pela complementaridade, exigindo uma atitude responsiva do leitor mais no sentido de compreensão da narrativa como um todo do que da relação entre as linguagens verbal e visual, além de abrir espaço para a reflexão acerca do conteúdo ideológico que constitui a história. Sutilezas do enredo, formado pelas linguagens verbal e visual, referendam que a interação com o título contribui para a ampliação dos horizontes do leitor e para a fruição estética.

Enfim, a leitura literária possibilita o brincar a partir da linguagem artística que se constitui a palavra e a imagem. Nesse sentido, o título do PNBE é um convite à diversão e à atuação do leitor. $\mathrm{O}$ apelo das cores e formas que caracterizam as personagens dialoga com o interesse do leitor infantil, assim como o dinamismo e a novidade do texto verbal possibilitam a construção de sentidos, exercício associado ao desenvolvimento subjetivo. Assim, é possível criar um campo de experiências culturais significativas para o leitor, incluindo seu repertório pessoal na depreensão de sentidos inerentes tanto às palavras, como às ilustrações e, ainda, pela interação das duas linguagens. Portanto, ler Ervilina e o Princês implica posicionar-se sobre o texto, em movimento de elaboração de sentidos, que emerge das diversas vias de expressão pelas quais a obra interage com o leitor.

\section{FOR EVERY TIME, A READER}


NEGRI, A. S.; RAMOS, F. B.; OLIVEIRA, L. G.

\begin{abstract}
The contemporary children's literature is a hybrid cultural product and it also consists of the updating of other texts which precede the most recent publication. Thus it is analyzed, based on Bakhtinian assumptions, the narrative Ervilina e o Pincês or Deu a louca em Ervilina (Orthof, 2009), to discuss probable interactions between the text (verbal or visual) and the reader. Based on the analysis, proposals of meaning which underlie the book are presented; relationships between the contemporary text and the source text - "The princess and the pea", of Andersen (2004) - are discussed, as well as between both editions of Orthof. The study is part of investigations that seek to approximate literary works of the child reader, at school environment, from the teacher's mediation, focusing on language practices that can promote the aesthetic experience and the literary literacy.
\end{abstract}

Keywords: Children Literature; Literary Literacy; PNBE [School Library National Program]; Childhood

\title{
PARA CADA TIEMPO, UN LECTOR
}

\section{Resumen}

La literatura infantil contemporánea es un producto cultural hybrid y también si constituye de la actualización de otros textos que preceden la publicación más reciente. De este modo, se analiza, en base de las hipótesis bakhtinianas, la narrativa Ervilina e o Princês ou Deu a louca em Ervilina (ORTHOF, 2009), con el fin de debatir sobre posibles interacciones entre el texto (verbal y visual) y el lector. Del análisis, se describen las propuestas de sentido que subyacen en la obra, sobre las relaciones entre el texto contemporáneo y la fuente - "La princesa y el guisante”, Andersen (2004) -, así como entre las dos ediciones de Orthof. El estudio se inserta en el curso de las investigaciones que buscan acercar las composiciones literarias del lector infantil, en la escuela, a través de la mediación docente, centrándose en las prácticas del lenguaje que pueden promover la experiencia estética y el letramento literario. 
Palabras-1lave: Literatura Infantil; Letramento Literario; PNBE; Infancia

\section{REFERÊNCIAS}

ADAM, Jean-Michel. Types de séquences textuelles élémentaires. Pratiques, Metz, 1987.

ANDERSEN, Hans Christian. Contos e histórias. 2. ed. São Paulo: Landy, 2004.

Aristóteles. Poética. Porto Alegre: Globo, 1966.

BARTHES, Roland. Introdução à análise estrutural da narrativa. In. BARTHES, Roland et. al. Análise estrutural da narrativa: pesquisas semiológicas. Tradução de Maria Zilda Barbosa Pinto. Petrópolis: Vozes, 1971.

BAKHTIN, Mikhail. Estética da criação verbal. Tradução: Pulo Bezerra. São Paulo: Martins Fontes, 2003.

DUARTE JUNIOR, João Francisco. Fundamentos estéticos da educação. Campinas, SP: Papirus, 2002.

FIORIN, José Luiz. Introdução ao pensamento de Bakhtin. São Paulo: Ática, 2008.

FORSTER, Edward. Aspectos do romance. Porto Alegre: Globo, 1969.

LOBATO, Monteiro. A menina do nariz arrebitado. In. Reinações de Narizinho. São Paulo: Brasiliense, 1993.

MARTINS, Maria Helena. O que é leitura. 17. ed. São Paulo: Brasiliense, 2006.

OLIVEIRA A, Rui de. Pelos jardins Boboli: Reflexões sobre a arte de ilustrar livros para crianças e jovens. Rio de Janeiro: Nova Fronteira, 2008.

ORTHOF, Sylvia. Il. Laura Castilhos. Ervilina e o Princês ou Deu a louca em Ervilina. Porto Alegre: Projeto, 2009.

ROSA, Sanny S. Brincar, conhecer, ensinar. São Paulo: Cortez, 2010.

SOARES, Magda. Alfabetização e letramento. São Paulo: Contexto, 2010.

TODOROV, T. As estruturas narrativas. Tradução: Leyla Perrone-Moisés. São Paulo: Perspectiva, 2004.

ZILBERMAN, Regina. A literatura infantil na escola. São Paulo: Global, 1998.

\section{LEGENDAS DAS IMAGENS:}


NEGRI, A. S.; RAMOS, F. B.; OLIVEIRA, L. G.

Fig. 1: Figuras isoladas na abertura do enredo - Fonte: Orthof e Castilhos (2009, p. 4-5).

Fig. 2: Apresentação da rainha - Fonte: Orthof e Castilhos (2009, p. 12).

Fig. 3: Amostra de página da primeira edição - Fonte: Orthof e Castilhos (2009, p. 44).

Fig. 4: Composição do humano - Fonte: Orthof e Castilhos (2009, p. 22).

Data de recebimento: $12 / 02 / 2015$

Data de aceite: 24/04//2015 